Reveal the release and transformation mechanism of polybrominated diphenyl ethers during the crushing of waste printed circuit boards based on the experimental monitoring and theoretical simulation

Honghuai Sun ${ }^{a}, \mathrm{Bo} \mathrm{Niu}^{a}$, Rui Wang ${ }^{a}$, Ruitong Gao ${ }^{a}$, Jie Guo ${ }^{a}$, Zhenming Xu ${ }^{a, b, *}$

${ }^{a}$ School of Environmental Science and Engineering, Shanghai Jiao Tong University, 800 Dongchuan Road, Shanghai 200240, P.R. China

b Shanghai Institute of Pollution Control and Ecological Security, Shanghai 200092, P.R. China

Corresponding author: Zhenming Xu Tel: +86 21 5474495; Fax: +86 21 54747495;

E-mail: zmxu@sjtu.edu.cn

Number of pages: 8

Number of tables: 4

Number of figures: 5

Table S1. The concentration distribution of isomers of penta-BDE

Table S2. The detailed equations and parameters of $k-\omega$ model

Table S3. The number of carriers with different size trapped in the wall

Table S4. The bond energy of bonds in different position in PBDEs congeners

Figure S1. The sampling methods of carriers

Figure S2. The chromatograms of each PBDEs congeners

Figure S3. The results of DPM of carriers 
Figure S4. The optimal position to be formed the carbon-hydrogen in PBDEs congeners

Figure S5. The transformation pathway of PBDEs 
Table S1. The concentration distribution of isomers of penta-BDE

\begin{tabular}{lllllll}
\hline & BDE-100 & BDE-119 & BDE-99 & BDE-116 & BDE-118 & BDE-155/85 \\
\hline $\begin{array}{c}\text { Concentration } \\
(\mathrm{mg} / \mathrm{kg})\end{array}$ & 17.397 & 5.672 & 5.677 & 2.778 & 2.866 & 1.153 \\
\hline
\end{tabular}

Table S2. The detailed equations and parameters of $k$ - $\omega$ model

\begin{tabular}{|c|c|}
\hline$P_{k}$ & $P_{k}=\min \left(\tau_{i j} \frac{\partial U_{i}}{\partial x_{j}}, 10 \beta^{*} k \omega\right)$ \\
\hline$F_{1}$ & $F_{1}=\tanh \left\{\left\{\min \left[\max \left(\frac{\sqrt{k}}{\beta^{*} \omega y}, \frac{500 v}{y^{2} \omega}\right), \frac{4 \sigma_{\omega 2} k}{C D_{k \omega} y^{2}}\right]\right\}\right.$ \\
\hline$F_{2}$ & $F_{2}=\tanh \left[\left[\max \left(\frac{2 \sqrt{k}}{\beta^{*} \omega y}, \frac{500 v}{y^{2} \omega}\right)\right]\right]$ \\
\hline$C D_{k \omega}$ & $C D_{k \omega}=\max \left(2 \rho \sigma_{\omega 2} \frac{1 \partial k \partial \omega}{\omega \partial x_{i} \partial x_{i}}, 10^{-10}\right)$ \\
\hline$v_{T}$ & $v_{T}=\frac{a_{1} k}{\max \left(a_{1} \omega, S F_{2}\right)}$ \\
\hline$\phi$ & $\phi=\phi_{1} F_{1}+\phi_{2}\left(1-F_{1}\right)$ \\
\hline$\alpha_{1}$ & $\frac{5}{9}$ \\
\hline$\alpha_{2}$ & 0.44 \\
\hline$\beta_{1}$ & $\frac{3}{40}$ \\
\hline$\beta_{2}$ & 0.0828 \\
\hline$\beta^{*}$ & $\frac{9}{100}$ \\
\hline$\sigma_{k 1}$ & 0.85 \\
\hline$\sigma_{k 2}$ & 1 \\
\hline$\sigma_{\omega 1}$ & 0.5 \\
\hline$\sigma_{\omega 2}$ & 0.856 \\
\hline
\end{tabular}

Table S3. The number of carriers with different size trapped in the wall

\begin{tabular}{ccccccccccccc}
\hline Diameter $(\boldsymbol{\mu m})$ & 10 & 9 & 8 & 7 & 6 & 5 & 4 & 3 & 2 & 1 & 0.6 & 0.3 \\
\hline Number of carriers & 77 & 76 & 58 & 52 & 41 & 33 & 19 & 19 & 17 & 15 & 16 & 14 \\
\hline
\end{tabular}




\section{The DFT calculation}

The calculations of structure of organic compounds were carried out with the Gaussian 16 program suite. Geometry optimization of the 4-OP was first done using the density functional theory (DFT) hybrid functional B3LYP combined with GD329 empirical dispersion correction and the def2-SVP basis set. Then, the energy was calculated by the DFT hybrid functional B3LYP combined with GD329 empirical dispersion correction and the def2-SVPP basis set.

Table S4. The bond energy of bonds in different position in PBDEs congener

\begin{tabular}{|l|l|}
\hline & Bonds energy (kj/mol) \\
\hline
\end{tabular}




\begin{tabular}{|l|l|}
\hline \\
\hline
\end{tabular}




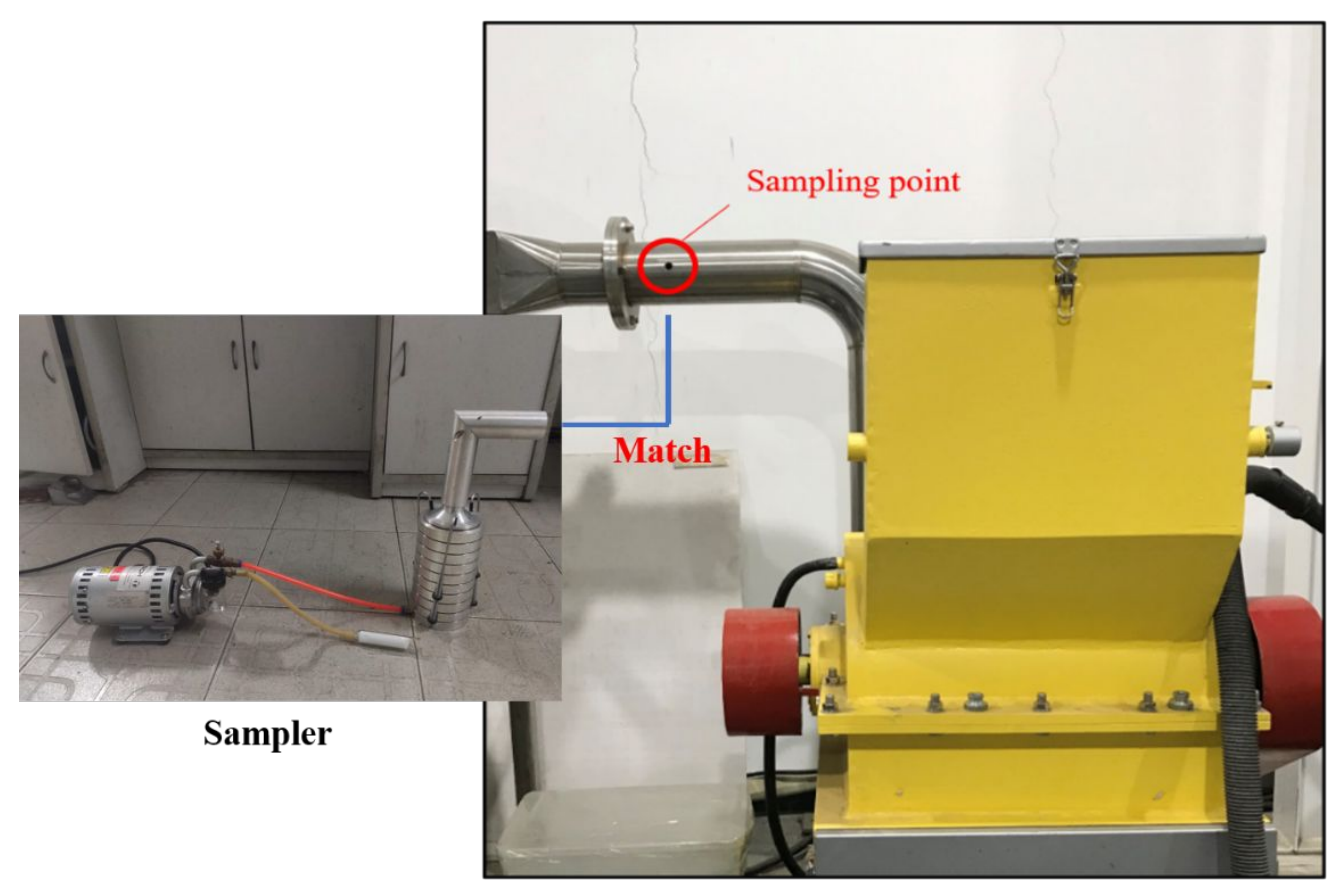

Figure S1. The sampling methods of carriers

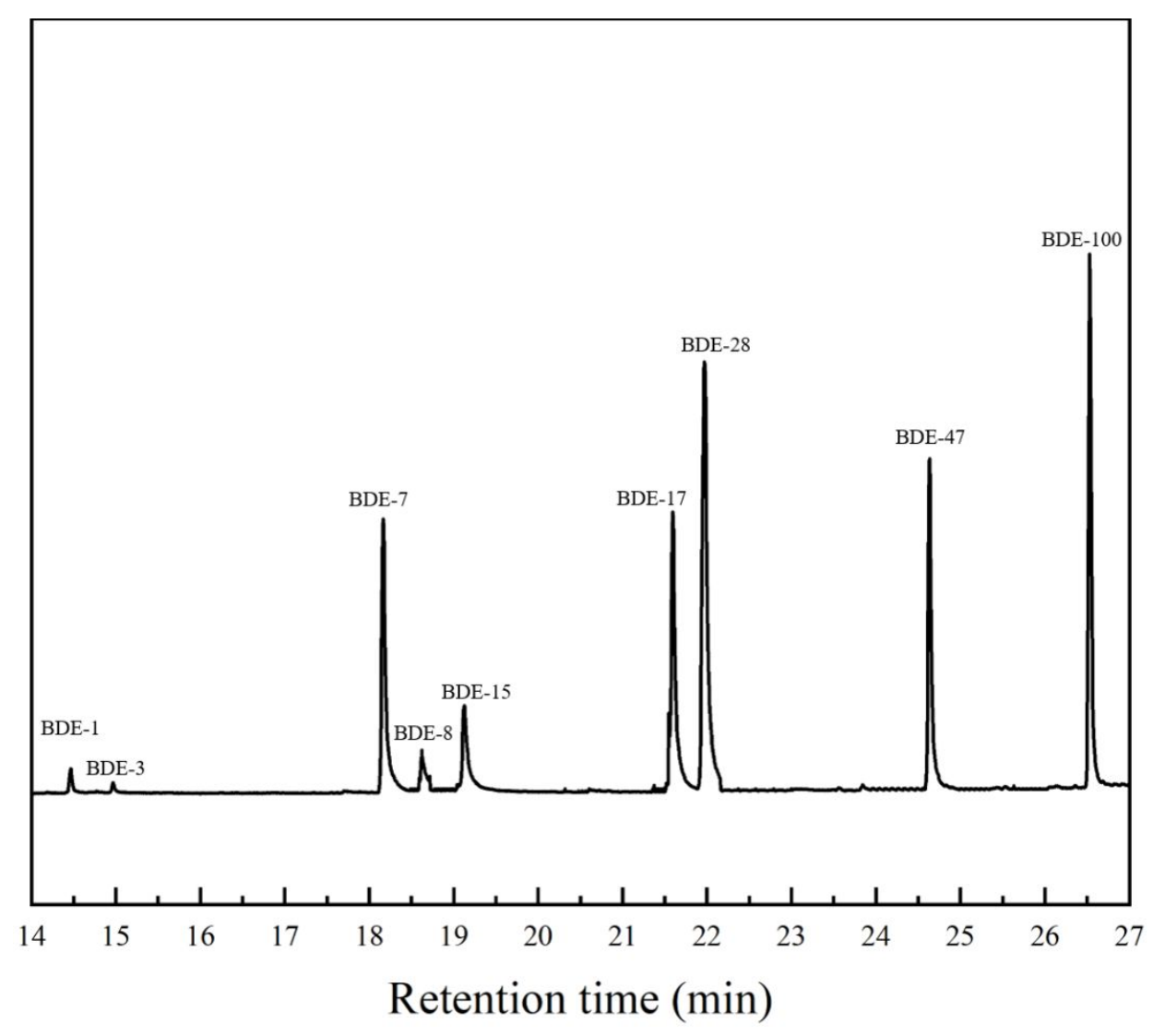

Figure S2. The chromatograms of each PBDEs congeners 


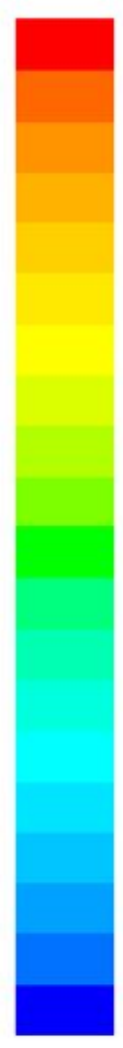

$1.00 \mathrm{e}-02$
$9.50 \mathrm{e}-03$
$9.01 \mathrm{e}-03$
$8.51 \mathrm{e}-03$
$8.02 \mathrm{e}-03$
$7.52 \mathrm{e}-03$
$7.03 \mathrm{e}-03$
$6.53 \mathrm{e}-03$
$6.04 \mathrm{e}-03$
$5.54 \mathrm{e}-03$
$5.05 \mathrm{e}-03$
$4.55 \mathrm{e}-03$
$4.06 \mathrm{e}-03$
$3.56 \mathrm{e}-03$
$3.07 \mathrm{e}-03$
$2.57 \mathrm{e}-03$
$2.08 \mathrm{e}-03$
$1.58 \mathrm{e}-03$
$1.09 \mathrm{e}-03$
$5.95 \mathrm{e}-04$
$1.00 \mathrm{e}-04$

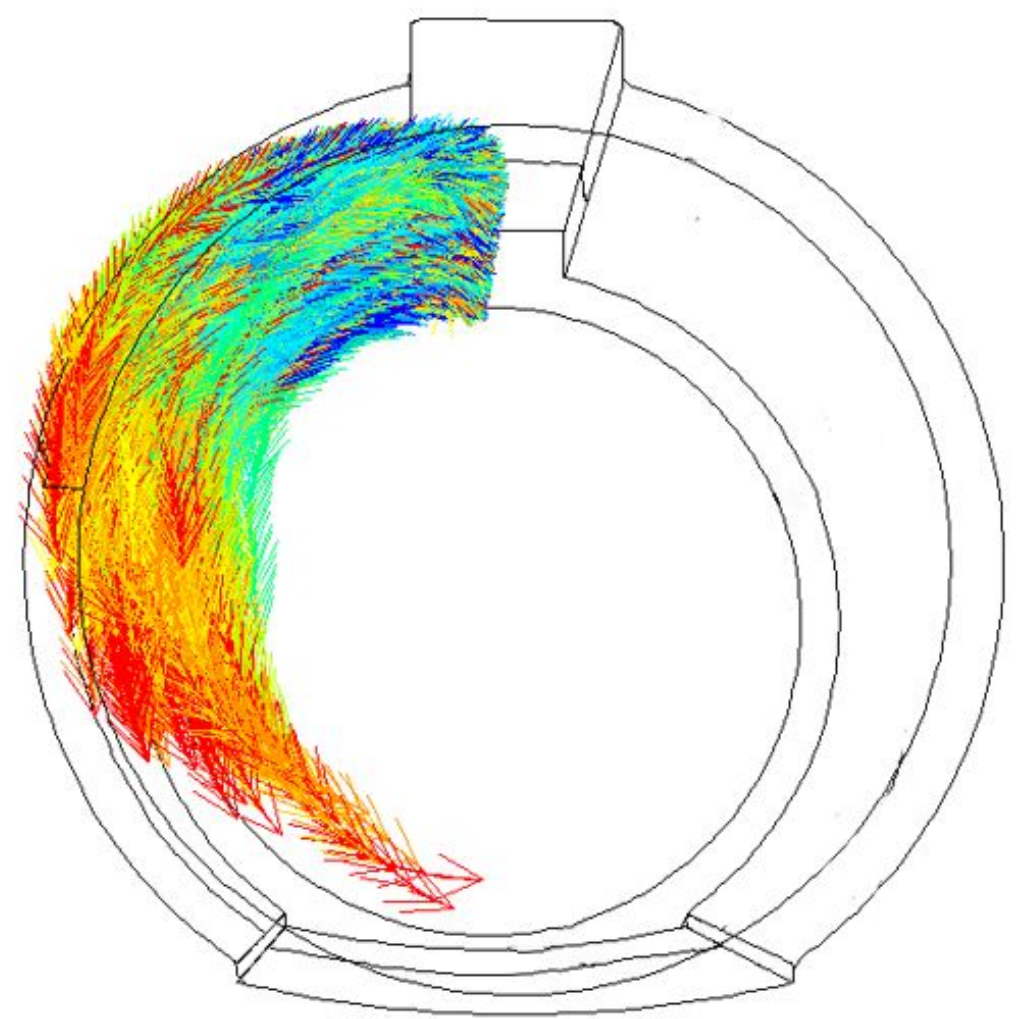

Figure S3. The results of DPM of carriers<smiles>Brc1ccc(Oc2ccccc2)c(Br)c1C(Br)(Br)Br</smiles><smiles>Brc1ccc(Oc2ccccc2C(Br)(Br)Br)cc1</smiles>

BDE-8<smiles>CC(Br)(Br)c1ccc(Oc2ccc(C(Br)(Br)Br)cc2)cc1</smiles>

BDE-15<smiles>FC(F)(Br)c1ccc(Oc2ccc(Br)cc2)c(Br)c1</smiles>

BDE-28<smiles>Brc1ccc(Oc2ccccc2Br)c(Br)c1</smiles>

BDE-17<smiles>FC(Br)(Br)c1ccc(Oc2ccc(Br)cc2Br)c(Br)c1</smiles>

BDE-47

Figure S4. The optimal position to be formed the carbon-hydrogen in PBDEs

$$
\text { congeners }
$$




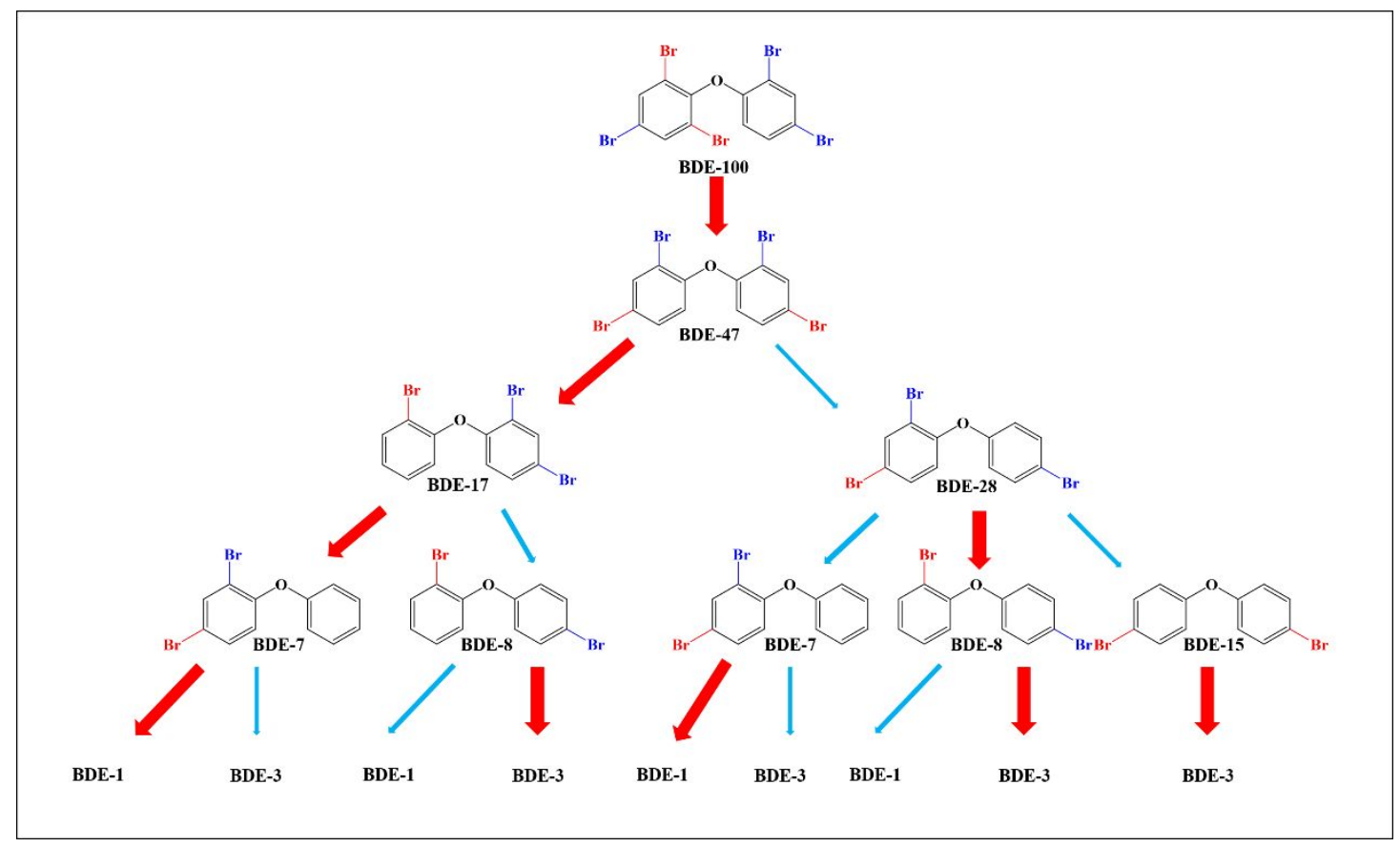

Figure S5. The transformation pathway of PBDEs 